\title{
Stereotype Threat Spillover: How Coping With Threats to Social Identity Affects Aggression, Eating, Decision Making, and Attention
}

\author{
Michael Inzlicht and Sonia K. Kang \\ University of Toronto Scarborough
}

\begin{abstract}
Stereotype threat spillover is a situational predicament in which coping with the stress of stereotype confirmation leaves one in a depleted volitional state and thus less likely to engage in effortful self-control in a variety of domains. We examined this phenomenon in 4 studies in which we had participants cope with stereotype and social identity threat and then measured their performance in domains in which stereotypes were not "in the air." In Study 1 we examined whether taking a threatening math test could lead women to respond aggressively. In Study 2 we investigated whether coping with a threatening math test could lead women to indulge themselves with unhealthy food later on and examined the moderation of this effect by personal characteristics that contribute to identity-threat appraisals. In Study 3 we investigated whether vividly remembering an experience of social identity threat results in risky decision making. Finally, in Study 4 we asked whether coping with threat could directly influence attentional control and whether the effect was implemented by inefficient performance monitoring, as assessed by electroencephalography. Our results indicate that stereotype threat can spill over and impact self-control in a diverse array of nonstereotyped domains. These results reveal the potency of stereotype threat and that its negative consequences might extend further than was previously thought.
\end{abstract}

Keywords: stereotype threat, self-control, stress and coping, neuroscience, ego depletion

In their now classic article, Steele and Aronson (1995) described a phenomenon called stereotype threat, a situational predicament in which individuals suspect their behaviors could be judged on the basis of negative stereotypes about their group instead of personal merit. According to this work, one of the reasons African American students tend to perform worse than Caucasians do is that stereotypes are "in the air" (Steele, 1997, p. 613), arousing deepseated fears and distracting them from doing as well as they could. Over a decade of research has followed this landmark article and has confirmed this basic view: When people consider stereotypes that target their groups, their performance tends to suffer in the stereotyped domain. What's more, performance is hurt by a broader category of events - it can occur whenever environmental cues hint that one's social identity makes one vulnerable to devaluation, when one feels like the victim of a social identity threat (Steele, Spencer, \& Aronson, 2002; see also, Tajfel \& Turner, 1986).

This article was published Online First July 12, 2010.

Michael Inzlicht and Sonia K. Kang, Department of Psychology, University of Toronto Scarborough, Toronto, Ontario, Canada.

This research was supported by grants from the Canada Foundation for Innovation, the Ontario Ministry of Research and Innovation, and the Social Sciences and Humanities Research Council to Michael Inzlicht. We thank Belle Derks, Colette van Laar, Jason Plaks, Alison Chasteen, and Kathleen Fortune for valuable insights. We also thank Winnifred Ip, Terry Ng, Francine Karmali, Marcella Wijaya, Criselda Gonzales, and Jeffrey Wong for their assistance with data collection.

Correspondence concerning this article should be addressed to Michael Inzlicht, University of Toronto Scarborough, Department of Psychology, 1265 Military Trail, Toronto, Ontario M1C 1A4, Canada. E-mail: michael.inzlicht@utoronto.ca
Whether discussing stereotype or social identity threat, almost all researchers have focused on consequences for performance in stereotyped dimensions. For example, according to research, stereotypes seem to affect the academic test performance of African Americans (Steele \& Aronson, 1995), math performance of women (Spencer, Steele, \& Quinn, 1999), athletic performance of Caucasians (Stone, Lynch, Sjomeling, \& Darley, 1999), driving performance of women (Yeung \& von Hippel, 2008), and intellectual performance of Latinos (Gonzales, Blanton, \& Williams, 2002) and children of low socioeconomic status (Croizet \& Claire, 1998).

The consequence of stereotype threat on performance in stereotyped domains, then, is widely documented, with over 180 separate articles examining performance deficits. ${ }^{1}$ In this article, however, we look beyond performance in stereotyped domains to a phenomenon we are calling stereotype threat spillover, which we define as a situational predicament whereby coping with negative stereotypes leaves one in a depleted volitional state and, thus, less able or willing to engage in a variety of tasks requiring effortful self-control. We suggest that stereotype threat has lingering effects that continue to influence people after they leave threatening environments, such that it has residual effects on behavior even in areas unrelated to the impugning stereotype.

In this article, we suggest that stereotype threat has a more far-reaching sphere of influence than previously thought, the result of which are behavioral difficulties in domains as disparate as aggression, eating, decision making, and paying attention. We

\footnotetext{
${ }^{1}$ We found 185 peer-reviewed articles when we entered the keywords stereotype threat and performance in the PsycInfo database on CSA Illumina on November 27, 2009.
} 
conceive of stereotype threat as a stressor and therefore as something with which people need to cope. Our central prediction is that this active coping response consumes self-regulatory resources, leaving people less able or willing to control and regulate themselves in instances in which self-control is required. What's more, we predict that even when people are able to cope effectively with threat and perform adequately in a stereotyped domain, because the act of coping is depleting, they will have difficulties regulating their behavior when they leave the threatening environment.

\section{What Is Stereotype Threat?}

At the most basic level, stereotype threat is a source of stress (Allison, 1998; Clark, Anderson, Clark, \& Williams, 1999; Pascoe \& Richman, 2009) and could be viewed within the broader framework of stress and coping models (Lazarus \& Folkman, 1987). According to a number of theoretical perspectives on coping with stigma (e.g., Major \& O’Brien, 2005; Miller \& Kaiser, 2001), stereotype and social identity threat, once appraised, could result in a number of physiological, emotional, cognitive, and behavioral reactions that are distinguished along the lines of voluntary and involuntary responses.

As soon as one makes an identity-threat appraisal, a series of involuntary stress responses takes hold. The possibility of failing one's group leads to a physiological stress response due to increases in arousal (Ben-Zeev, Fein, \& Inzlicht, 2005; Blascovich, Spencer, Quinn, \& Steele, 2001; O’Brien \& Crandall, 2003) and distracting thoughts (Cadinu, Maass, Rosabianca, \& Kiesner, 2005) that consume limited working-memory capacity (Beilock, Rydell, \& McConnell, 2007; Schmader \& Johns, 2003). These involuntary responses are accompanied by voluntary coping strategies. Essentially, individuals are motivated to disconfirm negative stereotypes (Steele \& Aronson, 1995). On an academic test, for example, targets expend great effort to perform well (Jamieson \& Harkins, 2007). However, once individuals confront the possibility of failing their group, they may cope by suppressing thoughts and denying uncomfortable emotions (Johns, Inzlicht, \& Schmader, 2008; Logel, Iserman, Davies, Quinn, \& Spencer, 2009).

In a recent model, Schmader, Johns, and Forbes (2008) integrate all of these recognized mechanisms and propose that stereotype threat leads to processing inefficiencies via depleted executive control. By integrating all the mechanisms underlying the stereotype threat effect, the authors offer the field a more complete appreciation of how these processes fit together. At the center of the model, acting as proximal mediator, is executive control. The more executive control that is used to manage the effects of stereotype threats, the less executive control remains for the central performance task.

Critically, this processing efficiency explanation suggests that stereotype threat need not always result in performance deficits in the stereotyped domain. In theory, a person under stereotype threat can perform at the same level as a nonthreatened person but would need to expend more energy and effort to do so (e.g., Inzlicht, Aronson, Good, \& McKay, 2006). That is, performance suffers only when one cannot cope with and compensate for the inefficient processing induced by threat by working harder and expending more effort (see Eysenck \& Calvo, 1992). Regardless of whether stereotype threat leads to performance deficits, it will lead people to exert more effort than if stereotypes were not in the air. It is this extra compensatory coping effort, we suggest, that is draining and can leave people depleted for subsequent tasks-especially tasks that require effortful self-control.

\section{Stress, Coping, and Self-Control Failure}

Self-control refers to a central volitional resource used to orchestrate a variety of intentional behaviors. It is the mental energy used to overcome environmental temptations and override urges, emotions, and automatic response tendencies. According to Baumeister and his colleagues, self-control is a limited, easily exhausted resource (Baumeister \& Heatherton, 1996; Muraven \& Baumeister, 2000). Empirical studies have confirmed that exerting control in one task impairs performance in another task, be that through less self-control capacity or lower motivation to engage in self-control (Robinson, Schmeichel, \& Inzlicht, 2010). For example, suppressing thoughts and emotions, which requires effortful control (Richards \& Gross, 2000; Wegner, 1994), can lead to later loss of self-control, as evidenced by inappropriate aggressive responding (DeWall, Baumeister, Stillman, \& Gailliot, 2007), overeating (Vohs \& Heatherton, 2000), overreliance on heuristics to make decisions (Masicampo \& Baumeister, 2008), and unfocused attention (Inzlicht \& Gutsell, 2007).

In the context of a stress and coping framework, stress can also contribute to self-control failure, usually because of attempts to cope. Many coping responses involve self-stopping and vigilance; for example, sensation blocking, thought suppression, emotion regulation, distraction, cognitive restructuring, avoidance, denial, and continuous self-monitoring are all resource-demanding (Compas, Connor-Smith, Saltzman, Thomsen, \& Wadsworth, 2001). Coping with stress, therefore, demands regulatory resources and, to the extent that these resources are limited, could lead to subsequent losses in self-control. For example, students who report high levels of stress also report lower states of self-control (Baumeister, Faber, \& Wallace, 1999). Similarly, stress in the form of unpredictable aversive noise or time pressure, results in less self-control, be that less persistence on a frustrating task (Glass, Singer, \& Friedman, 1969), increased risk taking (Holding, Loeb, \& Baker, 1983), or impaired attention control (Hochman, 1967). It is important to note that it is not stress by itself that is depleting; rather, the depletion of resources results from the individual's coping efforts (Baumeister et al., 1999).

Given that self-control is limited and that stereotype threat taxes it, we propose that stereotype threat will leave people with fewer volitional resources to perform-even on nonstereotyped tasks. That is, we hypothesize that coping with the stress of stereotype threat can have aftereffects by hurting performance on any task that requires self-control. Managing the stress of negative stereotypes involves resource-demanding coping strategies, such as emotion regulation and thought suppression (Johns et al., 2008; Logel et al., 2009), and because these resources are finite, coping could result in poorer self-control even after the stereotype stressor is no longer in the air. In short, we hypothesize that coping with stereotype and social identity threat can spill over and lead to a host of maladaptive behaviors and responses.

Although prior research is consistent with this hypothesis, to our knowledge, no research has examined how coping with stereotype stress can spill over onto commonplace tasks directly. Inzlicht, McKay, and Aronson (2006) found that stigma can consume 
self-regulatory resources. In one study, for example, they found that women exhibited poor physical stamina immediately before they thought they would take a threatening math test. Although this result appears similar to spillover, it is important to note that the self-regulatory depletion in this set of studies consisted of intervening variables between stereotype threat induction and test performance, before spillover could occur. It therefore sheds light on one of the processes through which stereotype threat operatesexecutive control depletion-but contextualizes this only within the threatening environment. Beilock and her colleagues (2007) also suggested the possibility of stereotype threat spillover, this time with women performing worse on a nonstereotyped verbal working memory task after having completed a threatening math test. Although this is consistent with our hypothesis, it is important to note that working memory is considered one of the processes through which stereotype threat operates (e.g., Schmader \& Johns, 2003), and showing deficits in such a closely related process variable is not evidence for the type of everyday spillover that we think is so important.

What is unique about our current model is that we predict threat will have residual effects even after participants leave the threatening environment. What is also unique is that we specify that it is the coping with threat, and not the threat itself, that leads to spillover. This is an important extension of Steele's (1997) original formulation because it speaks to the lingering effects of the usual way people cope with threat, adding barriers to the effective control of one's behavior and therefore capable of spilling over onto mundane, "real-world" domains such as aggression, eating, and decision making.

\section{Overview of Studies}

In the experiments we report here, we tested our prediction that coping with stereotype and social identity threat could spill over and affect behavior in nonstereotyped domains. In Study 1, we explored whether the experience of taking a threatening math test could spill over and lead women to respond with hostility compared with women taking the same math test but given an adaptive coping strategy. In Study 2 we tested whether coping with stereotype threat would lead women to eat unhealthy food and also whether personal traits that contribute to identity-threat appraisals, namely stigma consciousness (Pinel, 1999), could exacerbate this effect. In Study 3, we examined whether vividly remembering an experience of coping with social identity threat results in risky decision making. Finally, in Study 4, we asked whether the experience of coping with threat could directly influence attentional control and, importantly, whether the effect was implemented by brain activity indicating inefficient performance monitoring.

\section{Study 1: Stereotype Threat and Aggression}

In Study 1, we ask whether coping with stereotype threat could spill over and affect women in a nonstereotyped domain: aggressive behavior. Although aggressive impulses are a common part of human life, normally these aggressive impulses are kept in check by self-control (e.g., Gottfredson \& Hirschi, 1990). When selfcontrol resources are depleted, however, impulses are given free rein and can result in aggressive behavior. Recent research, for instance, has indicated that participants respond more aggressively to an insult after their executive resources are depleted (e.g., DeWall et al., 2007; Stucke \& Baumeister, 2006). If coping with stereotype threat depletes executive resources, it could reduce inner restraints against aggression, thus leading to more aggressive behavior, even among groups not stereotyped as being aggressive (e.g., women).

In this experiment, pairs of female participants completed tests of mathematical ability and then received negative feedback, ostensibly from their partner. One group of women was provided with an effective strategy for coping with this threatening situation, whereas the other group was not provided with any coping instructions. Following this, participants completed a measure of laboratory aggression, which operationalizes aggression as the intensity and duration of white noise blasts delivered to a partner (Bushman \& Baumeister, 1998). We should stress here that both groups of women in this study faced the same stereotype stressor (a challenging math test) and should therefore have experienced the same affect-related consequences. The only difference between these two groups was the type of coping engaged in to deal with the stereotype threat situation. Because the inhibition of aggression requires self-regulatory resources, we predicted that women who had just experienced stereotype threat would react more aggressively (e.g., volume and duration of adverse noise) after provocation than would women who had taken the same exam but were provided with an adaptive coping strategy. We also hypothesized that if success during a stereotype threatening test is partly indicative of how hard people work to overcome the stereotypes in the air, then the higher women score on the threatening test, the more depleted and, therefore, more aggressive they will become afterward.

\section{Method}

Participants. Thirty-four female University of Toronto Scarborough introductory psychology students who reported awareness that women are stereotyped as being worse than men in math ability participated in exchange for course credit. We excluded three participants (one from the threat condition and two from the reappraisal condition) because they were extreme outliers on the aggression measure, as computed by the extreme studentized deviate $(\mathrm{ESD})$ statistic, $\operatorname{ESD}(34)=4.57, p<.001$. Participants were randomly assigned to one of two conditions: stereotype threat or stereotype threat plus cognitive reappraisal.

Materials and procedure. Upon arriving at the lab, pairs of participants were greeted by a male experimenter who informed them that they would be participating in two separate tasks with a partner: an academic test completed independently with partner feedback and a competitive reaction time task. The experimenter then gave participants $5 \mathrm{~min}$ to get to know each other.

For the first task, participants were seated in individual cubicles and informed that the task was designed to investigate the relationship between mood and academic performance and that they would each have a chance to grade and provide feedback on their partner's test. Participants began by completing the five-item Math Identification Questionnaire (Brown \& Josephs, 2000), a 7-point Likert questionnaire measuring the importance individuals place on their mathematical abilities (e.g., "Doing well on math-related tasks is important to me"; $M=5.37, S D=1.40 ; \alpha=.83$ ). We administered this scale to control for differences in identification 
with the stereotyped domain, something known to predict susceptibility to stereotype threat (Aronson et al., 1999).

Participants then completed a math test that was diagnostic of their genuine math abilities and could indicate their strengths and weaknesses in the quantitative domain. Some research has suggested that stereotype threat is the default state of normal test taking for stereotyped groups and that no special effort is needed to create it in the laboratory; instead, effort is needed to take it away (e.g., Brown \& Day, 2006). Therefore, to turn stereotype threat off, we gave half the participants an extra set of reappraisal coping instructions, adapted from Richards and Gross (2000). Specifically, we asked participants to view the test objectively and to adopt a neutral attitude as they prepared for and completed the test. By reappraising the situation, participants were armed with an effective coping strategy to curb their natural inclination to cope with stereotype stress by suppressing their thoughts and emotions (Johns et al., 2008). Participants were given $10 \mathrm{~min}$ to complete one of two 10-item math tests constructed from a Graduate Record Examination test manual and designed to be equally difficult on the basis of past test results. We calculated test performance as the raw score corrected for errors (Spencer et al., 1999). Partners were matched in terms of whether they received cognitive reappraisal instructions, but we had them complete different math tests in order to prevent them from forming an opinion of their own performance while grading each other's exams.

After completing the math test, partners exchanged test papers for grading. Participants were given $10 \mathrm{~min}$ to grade the exam from an answer key and to provide general comments. Then the experimenter gathered the score sheets and left the room, ostensibly to make copies of these sheets. Upon returning, the experimenter provided each participant with the score sheet supposedly completed by the partner. All participants received the same false feedback: a low test score ( 3 out of 10 correct) and this negative comment: "This is a very bad score. I wouldn't be surprised if this is the lowest score in the group." We gave everyone negative feedback because past research has indicated that depleted capacity for self-regulation will result in aggressive responding only after participants are sufficiently provoked (DeWall et al., 2007).

Immediately after receiving the negative feedback on the academic test, participants completed the Positive Affect Negative Affect Schedule (PANAS; Watson, Clark, \& Tellegen, 1988) and measures of the performance component of the State Self-Esteem Scale (SSES; Heatherton \& Polivy, 1991) to assess current mood and state self-esteem, respectively. The PANAS consists of 10 positive (e.g., strong, enthusiastic) and 10 negative (e.g., hostile, nervous) adjectives; participants indicate how much they currently feel each emotion on a 5-point scale. The 7-item performance component of the SSES measures state self-esteem on 7-point Likert scales (e.g., "I feel confident in my abilities").

Participants then put on headphones and sat at separate computers for the competitive game. Although participants believed they would be playing against their partner, responses were computerized. Following the procedure of Bushman and Baumeister (1998), participants were told to press a button as quickly as possible when a stimulus appeared on the computer screen and, further, that whoever responded faster would deliver a blast of white noise to the slower partner. Prior to each of the 25 trials, participants chose a noise level (from 0 to 10) and duration (from 0 to 10) that their partner would receive for responding more slowly. Past research has shown that the first trial provides the best measure of unprovoked aggression because participants have yet to receive aversive blasts of white noise from their opponents (Bushman \& Baumeister, 1998; DeWall et al., 2007). Therefore, we used noise intensity and duration levels from the first trial, calculated as the interaction of the two, as our measure of aggression. After completing the computer game, participants were thanked and debriefed.

\section{Results and Discussion}

Aggressive behavior. Our main prediction was that the experience of stereotype threat will result in self-control failure such that those who have to cope with it "naturally" will respond more aggressively than will those who cope by cognitively reappraising their emotions. We analyzed the data with a one-way analysis of covariance (stereotype threat vs. cognitive reappraisal), covarying for math identification. Aggression scores were log-transformed due to skew and nonnormality; untransformed means are graphed for ease of interpretation. Figure 1A illustrates that the results are consistent with our prediction: After we controlled for math identification, which was a significant covariate in our analysis, $F(1$, $28)=6.68, p<.02, d=0.98$, participants in the threat condition were significantly more aggressive $(M=1.11, S D=0.38)$ than were participants in the reattribution condition $(M=0.96, S D=$ $0.37), F(1,28)=4.42, p<.05, d=0.79$. In other words, negative stereotypes about women's math ability affected their behavior in

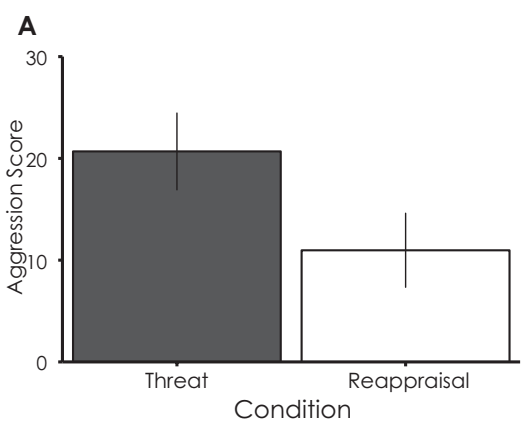

B

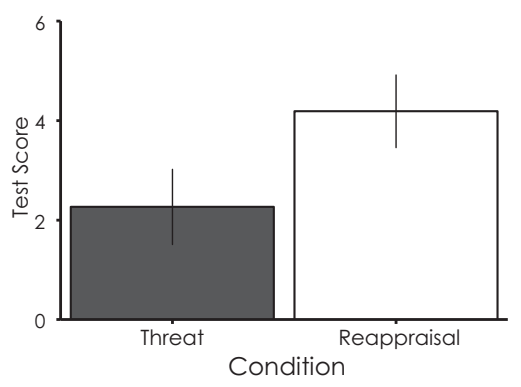

Figure 1. Results for Study 1 examining (A) aggression scores and (B) test performance as a function of threat condition. 
a domain not only unrelated to the stereotyped domain in question but also counterstereotypical for women more generally (Buntaine \& Costenbader, 1997).

Importantly, these results emerged after controlling for math identification, with greater identification significantly predicting aggression. This means that the more participants cared about math, the more aggressive they became toward their critical partners. By controlling for this, we are in fact controlling for those who likely got most upset by the negative feedback; and the fact that the threat manipulation had an effect over and above this covariate suggests that anger alone cannot account for our results but that something else is necessary. This something else, we suspect, is the inability to restrain impulses brought about by anger, an inability that comes about by coping with stereotype threat.

Math performance and negative affect. After examining these results pertaining to aggression, we turned our attention to results related to mood and performance on the math test. We expected to find evidence of the classic stereotype threat performance effect, such that participants who did the usual things to cope with taking a diagnostic math test would perform worse than did those who coped by cognitively reappraising their emotions. After determining that the two versions of the math test were equivalent, $F(1,28)=1.45$, $n s$, we proceeded to this main analysis. Figure 1B illustrates that results are consistent with predictions: Participants in the threat group performed worse $(M=2.27$, $S D=2.58)$ than did participants in the reattribution group $(M=$ $4.19, S D=3.21), F(1,28)=3.34, p=.078, d=0.69$. Although these results approached significance, the medium effect size is larger than the average effect size reported in the stereotype threat literature (average $d=0.48$; Walton \& Cohen, 2003).

We also measured affect and performance state self-esteem to determine whether our manipulation affected mood and, if so, whether it could account for the effect on aggression. We did not expect that stereotype threat would affect these explicit, self-report ratings, consistent with past research on stereotype threat (e.g., Johns et al., 2008) and on the limited resource model of selfcontrol. We calculated state affect by subtracting negative affect from positive $(M=0.84, S D=1.15 ; \alpha=.88)$ and calculated performance state self-esteem by reverse-scoring relevant items and then averaging them $(M=3.39, S D=1.27 ; \alpha=.86)$. As predicted, neither mood nor state self-esteem was affected after coping with stereotype threat (both $F \mathrm{~s}<1, n s$ ). Furthermore, when we reanalyzed the aggression scores, with affect or performance self-esteem as a covariate, the results were virtually unchanged, suggesting that the effects of stereotype threat on aggression cannot be attributed to either self-reported negative affect or low state self-esteem.

Given our failure to find an effect for the overall PANAS, we decided to investigate specific mood items in a theoretically derived way. Specifically, there are two relevant emotions that should be related to stereotype and social identity threat: anxiety and anger. Anxiety is part of the known mechanism of stereotype threat. Anger, on the other hand, is the most typical emotion experienced during social identity threat (Swim, Hyers, Cohen, \& Ferguson, 2001; Vescio, Gervais, Snyder, \& Hoover, 2005) and has been related to poor performance following experiences with discrimination (Gervais \& Vescio, 2007). It is especially important to examine anger because if stereotype threat increases it, this would allow for a clear alternative to our model - that threat increased aggression because it left people angry and not because coping with threat left them unable to restrain their impulses. When we reanalyzed the specific PANAS items related to anxiety ("nervous" and "jittery") and anger ("hostile"), however, it did not reveal any condition effects (all $F \mathrm{~s}<1, n s$ ). We also reanalyzed aggression scores with the specific anxiety and anger items as covariates, but the results were virtually unchanged, again suggesting that aggression was not the result of anxiety or anger. Thus, an increase in negative emotionality generally or anxiety and anger specifically cannot account for our results.

Frustration versus depletion. These results are consistent with our predictions and the classic stereotype threat performance effect. However, because performance did vary across groups, it is possible that the spillover onto aggression could be attributed to a feeling of lower self-efficacy or even frustration on the part of the threatened participants. That is, participants in the threat condition may have become frustrated because of their lower performance on the test and become aggressive as a result (Dollard, Doob, Miller, Mowrer, \& Sears, 1939). If this were the case, we should find a negative correlation between performance and aggression in the threat condition.

In contrast, if the loss of self-control explanation is valid, we should find a positive correlation between performance and aggression. Recall that not everyone underperforms during stereotype threat (Inzlicht, Aronson, et al., 2006); some people can compensate for cognitive inefficiencies produced by threat by working harder and expending more effort. Even though this extra effort can result in superior performance, we suspect that the harder individuals work to overcome stereotype threat, the fewer executive resources they will have to restrain their aggressive impulses. Thus, a self-control explanation predicts that the better participants perform on the test in the threat condition, the more aggressive they will be afterward.

Analysis of the correlations within both the threat and reappraisal conditions confirm the self-control, but not frustration, explanation. Results indicate that the better that threat participants performed on the math test, the more aggressive they tended to become, $r(15)=.46, p=.04$ (one-tailed). In contrast, there was no correlation between performance and aggression in the reappraisal condition, $r(16)=.01, n s$. Importantly, the correlation between performance and aggression remained unchanged after controlling for general affect, the specific emotions of anxiety and anger, or state self-esteem, countering any suggestion that highscoring participants felt justified in punishing their partners because they felt frustrated and upset by what they may have perceived as unfair feedback. Instead, we suggest, participants were more aggressive because they had just worked hard to try to overcome stereotype threat and did not have enough energy to restrain their aggressive impulse.

The results of this study support our hypothesis that coping with a threatening math test could spill over and affect domains unrelated to the impugning stereotype, in this case aggressive behavior. This suggests that stereotype threat not only leads to poor performance but also has lingering effects, affecting something as important as whether someone acts aggressively. These effects cannot be accounted for by losses in self-efficacy, stress alone, or increases in anger or frustration but are consistent with a loss of self-control account. 
It is important to note that the only difference between our two groups was that one was given a coping strategy to manage emotions adaptively, whereas the other likely coped by using a strategy of suppression and inhibition (Johns et al., 2008; Logel et al., 2009). Remember, both groups faced the same stereotype stressor and experienced the same types of affect. What separated them, then, was not stress but coping, and it is the work involved in coping with stereotype threat that we suggest can result in subsequent self-control loss (see Baumeister et al., 1999).

Although the data from Study 1 support our predictions, we could make a more solid case by addressing some design weaknesses. First, we did not include a comparison group. It is thus possible that those who reappraise their emotions as they take a difficult test - whether or not they appraise the situation as identity threatening - will become less emotionally invested and thus less prone to aggress than will people who do not reappraise their emotions. In Study 2, therefore, we included participants who were high and low in stigma consciousness (Pinel, 1999), and although we still expected to find a main effect for threat, we expected the spillover to be exacerbated for those who tend to appraise their environments as identity threatening. Second, as we have already noted, performance varied across group. Although the data are inconsistent with spillover being due to lower performance, it would be important to control for this, something we accomplished by using a difficult test that was thus equally frustrating for all participants.

\section{Study 2: Stereotype Threat and Eating}

In Study 2, we ask whether coping with stereotype threat can spill over and affect another type of nonstereotyped behavior: eating. Healthy eating requires that people monitor food intake and overcome temptations to eat high-calorie, high-fat food, both of which require self-regulatory resources to be successful. Vohs and Heatherton (2000), for example, found that those who resist food temptation have fewer executive resources afterward and that having fewer resources leads to more unhealthy eating. If stereotype threat consumes executive resources, it should also reduce the ability to overcome the impulse to eat tempting foods.

Participants were women identified as high or low in genderbased stigma consciousness. Participants completed a difficult math test in a standard stereotype threat condition or in a condition in which they coped with stereotype threat with cognitive reappraisal. Following the math test, participants took part in a "taste test" of three ice cream flavors. We hypothesized that after experiencing stereotype threat, participants who were not armed with an effective coping strategy would eat more ice cream than would those who also experienced threat but were armed with an effective coping strategy. Importantly, we expected that this pattern would be magnified for women high in stigma consciousness, an individual difference variable known to affect threat appraisals and to moderate stereotype threat (Brown \& Pinel, 2003).

\section{Method}

Participants. Forty-nine female University of Toronto Scarborough first-year psychology students $\left(M_{\text {age }}=18.10, S D=0.96\right)$ who reported awareness of the female/math stereotype participated for course credit. We failed to record the food weight for three participants, leaving us with 46 participants. Participants also completed the gender-based Stigma Consciousness Questionnaire (Pinel, 1999; $M=4.12, S D=0.86 ; \alpha=.73$ ) and the Restrained Eating Scale (Herman \& Polivy, 1980; $M=13.00, S D=7.34$; $\alpha=.78$ ) during mass testing. The 10 -item Stigma Consciousness Questionnaire measures awareness of gender stereotypes and sensitivity toward being the target of sexism (e.g., "Most people have a lot more sexist thoughts than they express"; responses were given on a 7-point Likert scale). The 10-item Restrained Eating Scale assesses preoccupation with eating and weight and is commonly used to identify chronic dieters (e.g., "Would a weight fluctuation of 5 pounds affect the way you live your life?"; responses were given on 4- or 5-point scales).

Materials and procedure. Participants were told that they would be taking part in a taste test and were asked to fast for $2 \mathrm{hr}$ before coming into the lab. At the lab, participants were greeted by a male experimenter, who framed the session as consisting of two separate studies - one on math performance and mood and one on taste preference.

Participants were randomly assigned to one of two conditions: stereotype threat or stereotype threat plus cognitive reappraisal. All participants were asked to complete a "genuine test of math intelligence." As in Study 1, women in the reappraisal conditions were further asked to cope with stereotype threat by reappraising their thoughts and feelings and thus avoiding their natural tendency to cope by thought and emotion suppression. To control for effects related to the experience of success (or failure) on subsequent self-control attempts, we used a difficult test so that all participants would perform equally poorly, thus avoiding suggestions that feelings of self-efficacy mediate our findings. That is, we designed the test so that all participants would perform equally but expected that participants in the threat group would have to work harder to get there. Participants were given 15 min to complete the 20 -item math test. Performance was calculated as in Study 1, with raw scores corrected for guessing. Right after the math test, participants completed the PANAS and the performance component of the SSES.

Next, the experimenter invited participants to take part in an unrelated study on taste preference. We adapted the classic tastetest paradigm, a widely used measure of eating (e.g., Vohs \& Heatherton, 2000), by presenting participants with three bowls, each containing three scoops of a different flavor of ice cream. Participants were given $10 \mathrm{~min}$ to complete a taste-test questionnaire assessing the likability of each flavor and were free to eat as much or as little of the ice cream as they wished. Our measure of self-regulatory ability was the weight in grams of ice cream eaten. After the taste test, the experimenter thanked and debriefed the participants.

\section{Results and Discussion}

We analyzed the data with a series of hierarchical linear regressions, entering condition (effect coded: $-1=$ threat, $1=$ reappraisal), mean-centered stigma consciousness, and the interaction between the two. Mean-centered restrained eating was entered as a covariate because eating poses a self-regulatory demand for those individuals with chronic inhibitions about eating (Vohs \& Heatherton, 2000). We probed significant interactions with simple slope analysis, examining the effect of condition for high and low 
stigma consciousness, coded as one standard deviation above and below the mean (Aiken \& West, 1991).

Eating behavior. We hypothesized that coping with stereotype threat "naturally" would leave women with fewer resources to control their intake of ice cream compared with women armed with a resource-saving coping strategy. We further expected this main effect to be exaggerated for high-stigma-conscious women because of their tendency to appraise a diagnostic math test as threatening, therefore needing extra resources to cope. Figure 2 shows that results confirmed our predictions.

Results justified our use of restrained eating as a covariate $(\beta=$ -.32), $t(41)=-2.24, p<.03, d=0.70$, and replicated a main effect for condition $(\beta=-.45), t(41)=-3.39, p<.03, d=1.06$, suggesting that threat group participants ate more ice cream after the math test than did reappraisal group participants. This main effect was subsumed under a marginal interaction between stigma consciousness and condition $(\beta=-.27), t(41)=-1.90, p<.07$, such that the effect of condition was significant for participants high $(\beta=-.71), t(41)=-3.61, p<.01, d=1.13$, but not low $(\beta=-.19), t(41)=-1.03, p>.30, d=0.32$, in stigma consciousness. $^{2}$

The experience of stereotype threat resulted in highly stigma conscious women eating significantly more ice cream than did women who coped with threat by reappraising their thoughts and emotions. All participants took the same diagnostic test; the only difference was that some participants were left to their own devices to cope with the stress of stereotype confirmation and others were encouraged to cope through resource-saving reappraisal techniques. This suggests that it is coping with negative stereotypes, and not the stereotypes themselves, that can result in a lingering spillover effect, in this case, overeating.

Mood, state self-esteem, and self-efficacy. We had participants take a difficult math test so that they would perform at about the same level and feel as good (or bad) about their performance. Thus, any effects of our manipulation on eating should not be attributed to decreases in general mood, state self-esteem, or self-efficacy. To examine this, we analyzed affect, performance state self-esteem, and math test performance. We calculated affect by subtracting negative affect from positive $(M=0.49, S D=$ $0.65 ; \alpha=.78)$, performance state self-esteem by reverse-scoring

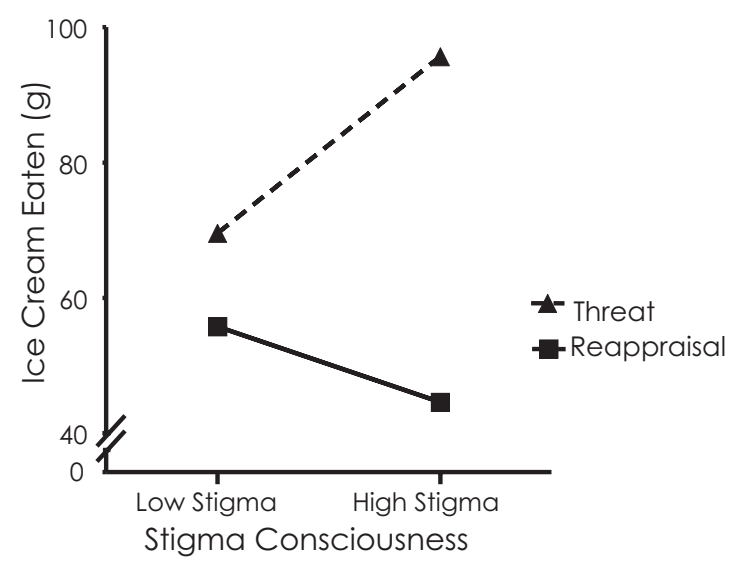

Figure 2. Grams of ice cream consumed as a function of stigma consciousness and threat condition. relevant items and then averaging them $(M=3.02, S D=0.82$; $\alpha=.88$ ), and math test performance by correcting the raw score for guessing, $(M=3.07, S D=4.22)$. As predicted, we did not find any condition or interaction effects for affect, state self-esteem, or math test performance (all $\beta \mathrm{s}<.2$ ), $t \mathrm{~s}<1.3$, ns. Participants performed as well and felt as good about themselves and their performance whether they coped naturally or by reappraising their emotions. Importantly, when we reanalyzed the eating data after controlling for these variables, the interaction was virtually unchanged (all $p \mathrm{~s}<.054)$.

As with Study 1, we also examined discrete emotions in a theoretically derived way. Past research specifically links social identity threat with anxiety (Ben-Zeev et al., 2005) and anger (Vescio et al., 2005), and it is therefore important to examine specific items on the PANAS (i.e., "hostile," "nervous," "jittery") here. Results revealed no significant condition or interaction effects for the items "hostile" and "jittery" (all $\beta s<.2$ ), $t \mathrm{~s}<1.3, n s$; however, they did reveal a trend for "nervous," such that participants experiencing stereotype threat felt somewhat more nervous than did those who coped with threat with cognitive reappraisal, even if this effect did not reach traditional levels of significance ( $\beta \mathrm{s}=-.24), t=-1.64, p=.11$. Of greater consequence, when we reanalyzed the eating data controlling for any one of these discrete emotions, all effects were the same (all $p$ s $<$.064). Taken together, these findings are inconsistent with an interpretation that the effects of stereotype threat on eating are a product of negative affect generally, anger or anxiety specifically, self-esteem, or frustrations due to a poor performance.

The results of this study support our hypothesis that coping with the stress of stereotype confirmation can spill over into the domain of eating, a domain unrelated to math. In contrast, women who were armed with an adaptive coping strategy left the threatening math environment more able to resist the temptation to eat unhealthy, albeit delicious, ice cream. This further indicates that coping with stereotype threat can have lingering effects, leading people to underperform in domains that are outside of the purview of the negative stereotype.

Thus far, we have shown that stereotype threat can spill over to nonstereotyped domains_-coping with stereotype stress can lead people to become more aggressive and to eat more unhealthy food. Importantly, these effects do not appear to be the product of

\footnotetext{
${ }^{2}$ We used restrained eating as a covariate in our analysis because eating poses an especially difficult self-regulatory demand for chronic dieters (Vohs \& Heatherton, 2000). An alternative strategy would be to enter into the model not only restrained eating but also the interaction between restrained eating and threat, restrained eating and stigma consciousness, and the three-way interaction between restrained eating, threat, and stigma consciousness. This would test whether the effect of threat among women high in stigma consciousness is limited to restrained eaters. Including these extra factors in our model, however, did not improve it, $\Delta R^{2}=.02, F(3$, $38)<1$, ns; furthermore, none of the extra variables was significant (all $t \mathrm{~s}<1, n s)$, most notably the three-way interaction, $t(38)<.2$, ns. It appears, then, that although it is critical to covary for differences in restrained eating, the effect of threat on eating was not restricted to chronic dieters. Although this seems at odds with the work of Vohs and Heatherton (2000), we note that other researchers have found that resource depletion results in overeating even among nonrestrained eaters when other factors are taken into consideration (e.g., Hofmann, Rauch, \& Gawronski, 2007)
} 
general affect, anger, anxiety, low self-esteem, or depressed selfefficacy. Although this provides a good foundation, we are missing direct evidence that spillover effects are due to expending limited self-regulatory resources. We address this limitation in the last two studies.

\section{Study 3: Social Identity Threat and Risky Decisions}

The goal of this third study was twofold: first to provide better evidence that identity threats are resource depleting and second to explore whether social identity threat could affect decision making. As with many cognitive processes (Chaiken \& Trope, 1999), decision making is thought to rely on dual systems: one that is quick and associative (System 1) and one that is deliberative and controlled (System 2; Kahneman, 2003). Decisions based on System 1, however, are prone to error and are often guided by System 2, which monitors and corrects decisions. Importantly, the deliberative system is resource-dependent and therefore susceptible to the limits of self-control capacity. Recently researchers have demonstrated, for example, that participants make more biased judgments and risky decisions after their executive resources become depleted (Masicampo \& Baumeister, 2008). If social identity threat depletes self-control resources, it should lead to choices biased by the automatic system, including risky choices.

In this study, we use a novel manipulation of threat by having participants vividly recall a time when they were the target of prejudice, a process that we suggest can be resource depleting. Recent research shows that simulating an experience of selfregulatory exertion can result in the same type of executive control depletion as can an actual act of exertion (Ackerman, Goldstein, Shapiro, \& Bargh, 2009). If so, then vividly reliving an experience of prejudice should elicit psychological effects consistent with the actual experience of such a situation. We suggest that such experiences elicit attempts to cope with the situation, which require people to restrain their natural impulses and suppress their thoughts and emotions. Coping with prejudice, we predict, can be resource depleting not only in the actual situation but also during its vivid simulation. We first conducted a pilot study using qualitative narrative analysis to determine whether recalling an experience of prejudice brings up memories of self-regulatory effort. We then examined the impact of this simulation on decision making.

\section{Pilot Study}

We conducted an initial pilot study to examine how members of stigmatized groups react when they make an appraisal of social identity threat. We asked 17 Black students at a Canadian university to recall a time when they experienced a negative outcome due to their race. We also asked participants to recall, as a comparison, a negative experience that was not related to race. Participants were given $30 \mathrm{~min}$ to complete these stories, and the topics (race bias or negative outcome) were presented in counterbalanced order. We coded these narratives for emotions and coping strategies. The focal question was whether participants would be more likely to regulate their feelings and behaviors in response to a race-based negative outcome than they would in response to a general negative outcome.
Results and discussion. Two independent judges, blind to hypotheses, coded the stories for the presence of a number of themes related to dealing with social identity threat: negative affect, anger, sadness, fear, contempt, stress, impression management, and self-suppression (the last coded as expressing efforts to control one's thoughts, actions, and emotions by inhibiting and suppressing them). As a manipulation check, the stories were coded for instances when a racial stereotype was being applied to the participant. The judges agreed with each other at a significantly high rate (average Kappa $=76 \%$, all $p \mathrm{~s}<.001$ ), and rating disagreements were resolved through discussion. As expected, almost all the stigmatizing stories described an event in which a stereotype was applied to the participant (88\%). On an absolute level, people's accounts of racial mistreatment tended to include (i.e., more than $50 \%$ of stories) elements of negativity $(88 \%)$; anger (53\%); stress $(71 \%)$; and, of greatest relevance to the current study, efforts at self-suppression (72\%). These results are consistent with past research (e.g., Vescio et al., 2005) as well as our current formulation. Comparing stigma events with general negative events further revealed the degree to which being threatened by negative stereotypes increases negative feelings and attempts to inhibit such feelings. Identity-threatening events included higher incidences of contempt ( $30 \%$ vs. $0 \%$ ), $z=2.24, p<.03$, and stress ( $71 \%$ vs. $47 \%), z=2.00, p<.05$, but also greater attempts to inhibit and suppress actions, thoughts, and feelings (72\% vs. 41\%), $z=2.24, p<.03$, and a trend toward greater impression management $(18 \%$ vs. $0 \%), z=1.73, p<.09$.

On the basis of these pilot results, it appears that threats to racial-group identity elicit greater emotionality and stress than do other negative experiences. Critically, it also elicits more attempts to suppress thoughts and emotions. Therefore, coping with threats to racial identity involves self-suppression, a process known to deplete self-control resources (Muraven \& Baumeister, 2000).

We next use the same basic simulation exercise to examine the effects of coping with social identity threats on decision making. Participants completed an abbreviated version of the simulation task and then completed a decision-making task requiring them to choose between one of two lotteries: one with a high likelihood of winning a small prize (high expected value) and a second with a low likelihood of winning a large prize (low expected value). Participants in the control condition completed the lottery decision task before the simulation task. Given the results of our pilot study, we hypothesize that participants who vividly recalled a threat to their racial identity would make the less "rational" choice and choose the riskier low-expected-value lottery. In contrast, we expected that those in the control condition, whose self-control resources were not depleted by the recall of an incidence of self-suppression, would go for the less risky high-expected-value lottery. Although we make the prediction on the basis of racebased threats, given our theoretical framework, we also expect the results to generalize to other identity threats.

\section{Method}

Participants. Participants were 118 (72\% female) University of Toronto Scarborough third-year psychology students $\left(M_{\text {age }}=\right.$ 22.8 years, $S D=2.43$ years) who participated as part of a class assignment. Our sample was diverse in terms of ethnicity $(36.1 \%$ South Asian, 31.1\% East Asian, 11\% White, 8.4\% Black, 5\% 
Middle Eastern, 1.7\% Latino, 1.7\% Biracial, 4.2\% Other) and religious affiliation $(38.7 \%$ Christian, 21\% Muslim, 16.8\% Atheist/Agnostic/Nonreligious, $15.1 \%$ Hindu, $2.5 \%$ Buddhist, $2.5 \%$ Sikh, $3.4 \%$ Other).

Of the 118 participants, 27 did not (or could not) write about an experience of discrimination and instead wrote about a negative event that did not involve discrimination. As such, our main analyses were conducted with 91 participants who were representative of our original sample in terms of gender, age, ethnicity, and religion. Our identity-threat condition consisted of 46 participants, and our control condition consisted of 45 participants. Of the 91 narratives, the majority were based on racial/ethnic discrimination $(35.3 \%)$. The remaining narratives were based on age $(13.4 \%)$, gender $(11.8 \%)$, religion $(10.1 \%)$, sexual orientation $(2.5 \%)$, or an "other" category (3.4\%, e.g., height, weight, mental illness).

Materials and procedure. Participants completed this study in a classroom setting. In the identity-threat condition, participants indicated their gender, age, sexual orientation, ethnicity, and religion and vividly remembered a time when they felt discriminated against because of their group membership in any one of the above five categories. Again, vivid simulations and reenactments of social identity threat should give rise to the same set of feelings and psychological processes as the actual experience of identity threat and leave participants in a comparable depleted state (Ackerman et al., 2009). Therefore, participants were told to recreate the experience as fully as possible by thinking about all of the thoughts, feelings, and sensations they had at the time of the experience. They were asked to think about how they coped and how they felt, both physically and emotionally. Participants were given $5 \mathrm{~min}$ to write this expressive narrative.

Following the writing exercise, participants completed an ostensibly unrelated questionnaire, a task modeled after the wellknown lottery choice tasks, considered a measure of risky decision making (Thaler \& Johnson, 1990). Participants read about two lotteries: Lottery A and Lottery B. The price of a ticket for each lottery was $\$ 5$, and participants were told that they could buy only one ticket. Lottery A, the low-risk choice, presented a $70 \%$ chance of winning a $\$ 20$ prize; Lottery $\mathrm{B}$, the riskier choice, presented a $4 \%$ chance of winning a $\$ 250$ prize. Lottery A has the higher expected value and is thus the safer choice.

Participants in the control condition completed the lottery decision task first and then completed the writing task. The participants who wrote about experiences with identity threats took part in both the threat and control conditions. The 27 participants who wrote about some negative life experience not involving prejudice also took part in both conditions, and these participants could therefore be examined as negative affect control groups.

\section{Results and Discussion}

We expected that participants in the threat condition, who vividly remembered an experience of coping with social identity threat before making a decision, would have fewer resources for System 2 correction and would thus be less likely to make the "rational" decision on the lottery task. As hypothesized, the percentage of participants who chose the risky lottery was significantly higher among the threat group $(52.2 \%)$ than the control group, $(26.7 \%), \chi^{2}(1, N=91)=6.19, p=.01$. One strength of this study is that we had people remember threats to their social identity on the basis of any number of social categories, and overall, the results are consistent with our hypothesis that coping with the stress of social identity devaluation-regardless of source-can spill over and affect decision making. To explore whether the category of threat made a difference, we broke down the omnibus comparison into the different types of social identity threats that participants described. Though we did not have the power to detect significant differences in all categories, Figure 3 illustrates that the trend is such that when people remembered threats to their social identity, they made riskier decisions. ${ }^{3}$ The only exception to this trend was with age: When our college-age participants described times when they felt discriminated against because of their (young) age, they showed a trend for being less likely to make the risky decision, although this effect was not significant $\left(\chi^{2}<1, n s\right)$.

It is notable that our largest effect occurred when participants recalled threats to racial identity, which our pilot study indicated involved stress and efforts to cope with stress. Although we assume that the types of situations recalled for religion, gender, and age are similar to those recalled for race in terms of emotions and self-regulation, we cannot verify this possibility with the current data. ${ }^{4}$ It is therefore possible that memories of threats to these other identities bring up different coping strategies, a possibility that may explain the weak or inconsistent effects with gender and age.

Results confirm our predictions that recalling a time when one coped with social identity threat can hurt effective decision making. But to what extent is this effect a product of self-control loss and not some other process? Although the current study cannot provide an unequivocal answer, referring to the results of the pilot test may be informative. There one can see that social identity threats, at least threats to racial identity, involved more stress and more attempts to control that stress by suppressing one's thoughts and feelings when compared with other negative life experiences. If stress and effortful coping with stress are to blame for the poor decision, then one would expect to find more risky decisions among the threat group than among the negative affect control. This is precisely what we found: Whereas $52.2 \%$ of participants in the threat group chose the risky lottery, $0 \%$ did so in the negative affect control, $\chi^{2}(1, N=57)=9.91, p<.01$. Furthermore, the negative affect group showed a trend of making fewer risky decisions when they relived their negative experience before the judgment task compared with after, $\chi^{2}(1, N=57)=3.02, p<.09$, consistent with results showing that negative mood can improve decision making (e.g., Bless et al., 1996).

Our results indicate that negative affect alone cannot account for the effects of social identity threat on decision making; rather, something else is necessary. That something else, we suggest, is self-control depletion brought about by efforts to cope with ste-

\footnotetext{
${ }^{3}$ We present data for only those social categories for which at least 14 participants recalled and wrote about their experiences. Thus, we did not graph participants who wrote about being stigmatized on the basis of sexual orientation $(n=2)$ or the "other" category $(n=3)$.

${ }^{4}$ Five minutes was enough time to allow participants to vividly reenact the incident but not enough to allow them to write about their experience extensively-on average, participants wrote about 90 words in five sentences, thus precluding a thorough content analysis of the narratives.
} 


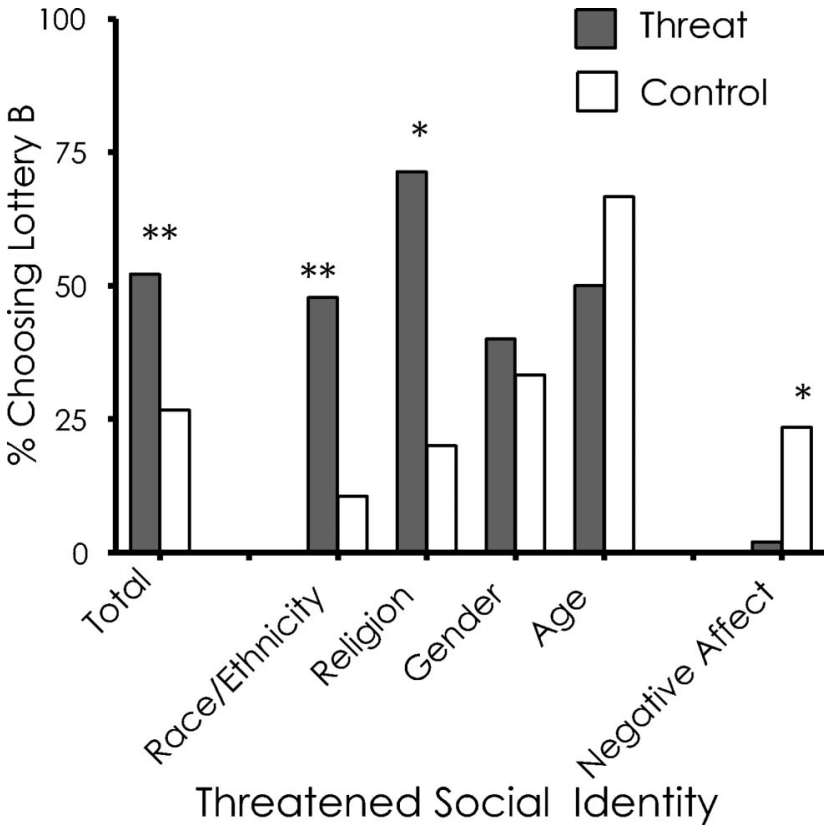

Figure 3. Percent of participants choosing Lottery B (high-risk, lowexpected value choice) as a function of threat priming condition. The first set of comparisons is for all participants, and the second set is broken down by specific social identity threatened. ${ }^{*} p<.09$. ${ }^{* *} p<.02$.

reotype stress. This is consistent with the view that coping with social identity threat and making rational choices, although unrelated in terms of domain, rely on a common limited resource. The depleting consequences of coping with prejudice spilled over onto the domain of decision making, reducing participants' ability to make the rational choice. Although this study is a step in the right direction, what is still needed is evidence of a direct link between threat and control, preferably with online measures of mediations and process; this was the aim of our final study.

\section{Study 4: Neural Signals for Stereotype Threat Spillover}

Studies 1-3 indicate that coping with stereotype threat can lead to an assortment of behavioral outcomes, many appearing like products of self-control failure. We have not, however, directly measured self-control; even though we have ruled out many alternative explanations, it is possible for aggression, overeating, and risky judgments to be attributed to other processes. In Study 4, we therefore measured performance on the Stroop color-naming task, a reaction-time measure of executive control, specifically the inhibition of an automatic reading response (Miyake et al., 2000).

To understand stereotype threat spillover, we also explored the neural mechanisms of self-control failure by looking at activity in the anterior cingulate cortex (ACC). The ACC is a brain area important for executive control (Botvinick, Braver, Barch, Carter, \& Cohen, 2001) and is implicated in stereotype threat and selfcontrol depletion (Inzlicht \& Gutsell, 2007; Krendl, Richeson, Kelley, \& Heatherton, 2008; see Derks, Inzlicht, \& Kang, 2008). In electroencephalograph (EEG) studies, the ACC is indexed by a set of medial-frontal event-related potentials (ERPs) thought to signal when attention and vigilance are needed, usually as a result of some anxiety-producing event such as making a mistake or facing response conflict (Gehring, Goss, Coles, \& Meyer, 1993). In inhibition tasks like the Stroop, these medial-frontal negative waveforms are present after error responses and after correct responses on high-conflict trials (e.g., "RED" in blue letters); in contrast, this wave is normally small on low-conflict trials (e.g., "RED" in red letters; Bartholow et al., 2005). Although there is agreement that these medial-frontal ERPs reflect performance monitoring, recent work casts doubts on a purely cognitive function for these waves (e.g., Hajcak \& Foti, 2008). Instead this work indicates that these ERPs are a product of affective responses to one's performance (Luu, Collins, \& Tucker, 2000), that they represent a neural "distress signal" indicating when attention and vigilance are needed (Bartholow et al., 2005, p. 41).

Given the importance of the ACC performance-monitoring system in executive control, factors that affect control should be reflected in this brain system. Recent work and theorizing confirms this view. In one study, not only did depleted participants experience self-control loss, but this loss was mediated by dampened, unresponsive ACC activity (Inzlicht \& Gutsell, 2007). Self-control failure can also come about through inefficient use of selfregulatory resources (Baumeister \& Heatherton, 1996), for example, through heightened vigilance for all types of events, even those not requiring effortful control. Theoretically this, too, should be reflected in the ACC, where medial-frontal waveforms would be high not only for errors and high-conflict trials but also for low-conflict trials, for which effort and control are not needed (Derks et al., 2008). In short, if coping with stereotype threat consumes executive resources, it would be evident in ACCgenerated ERPs, as either dampened or inefficient ACC-based performance monitoring.

As in Studies 1 and 2, we induced stereotype threat by giving female participants a "diagnostic" math test, with women in one group further encouraged to cope with threat by reappraising their emotions. We also ran a control group of male participants. Participants then completed the Stroop color-naming task while we measured EEG. We predicted that coping with the stress of stereotype confirmation would spill over into a second, unrelated domain, in this case women's ability to inhibit automatic reading responses on a Stroop task compared with men and with women given an effective means to cope. We further predicted that impaired Stroop performance would be mediated by disruptions to medial-frontal ERPs.

\section{Method}

Participants and design. Participants were 52 students (37 female; $M_{\text {age }}=18.83$ years, $S D=1.7$ ) from the University of Toronto Scarborough. Ten participants were excluded from analyses due to equipment malfunction (4), extensive EEG artifacts (4), or outlying EEG scores (2). Women were randomly assigned to either diagnostic $(n=15)$ or reappraisal $(n=14)$ conditions. Men $(n=13)$ participated in the diagnostic condition.

Procedure. Participants were fitted with an electrode cap for EEG recording and then given 15 min to complete a 20 -item math test. All participants learned that the test was a "genuine test of math intelligence," but women in the reappraisal condition were encouraged to reappraise their emotions as they took the test. Male 
participants took the same "diagnostic" test without reappraisal instructions. As with Study 2, we used a difficult test so that all participants would perform equally, thereby controlling for effects related to the experience of high or low self-efficacy. We calculated performance with raw scores corrected for guessing. Following the test, participants completed an ostensibly unrelated taskthe Stroop-at which point we started measuring continuous EEG.

Stroop stimuli were the words red and green presented in either red or green letters. Participants responded to each stimulus by pressing the appropriate button on a response box. A fixation cross appeared for $500 \mathrm{~ms}$, then the stimulus word appeared for $200 \mathrm{~ms}$; the maximum response window was $800 \mathrm{~ms}$. On congruent trials, a color word appeared in a color matching its semantic meaning; on incongruent trials, it mismatched the semantic meaning. Participants completed 10 blocks with 32 congruent and 16 incongruent trials each. Stroop incongruency was based on correct responses only and was calculated by subtracting the mean response time for congruent trials from the mean of incongruent trials and by winsorizing this difference with a low end of $10 \mathrm{~ms}$ and a high end of $100 \mathrm{~ms}$ to correct for deviations from normality.

EEG was recorded from 32 silver/silver chloride-sintered electrodes embedded in a stretch Lycra cap. Vertical eye movements (VEOG) were monitored via a supra- to suborbital bipolar montage. EEG and VEOG were digitized at $512 \mathrm{~Hz}$ with ASA acquisition hardware (Advanced Neuro Technology, Enschede, The Netherlands) with an average electrode reference and forehead ground. To analyze the medial-frontal negative waves, we followed the same basic analysis strategy as did Bartholow and his colleagues (2005). Continuous EEG was corrected offline for blink artifacts using a standard procedure (Gratton, Coles, \& Donchin, 1983), and frequencies below $1 \mathrm{~Hz}$ and above $15 \mathrm{~Hz}$ were digitally filtered. We baseline-corrected the signal by subtracting the average voltage $500 \mathrm{~ms}$ to $300 \mathrm{~ms}$ before key press. Artifacts were automatically detected with $-75 \mu \mathrm{V}$ and $+75 \mu \mathrm{V}$ thresholds. For each artifact-free trial, a 1,100-ms epoch of EEG signal locked on button press was selected for averaging. ERPs for error trials and congruent and incongruent trials were averaged across participants and grand-averaged within respective conditions. The negative polarity waves were quantified as the peak minimum deflection between $50 \mathrm{~ms}$ pre- and $150 \mathrm{~ms}$ postresponse at the frontal midline electrode $(\mathrm{Fz})$.

\section{Results and Discussion}

Behavioral control. We expected that coping with stereotype threat would affect inhibitory control, and this is precisely what we found. Results reveal a Stroop incongruency effect that differed across the three groups, with contrast analyses indicating that diagnostic group women $(M=28.39, S D=27.22)$ had more Stroop interference than did men $(M=15.29, S D=13.78)$ or reappraisal group women $(M=12.91, S D=8.42), t(39)=-2.38$, $p<.03, d=0.76$. Reappraisal group women, on the other hand, performed equally to men, $t(39)=-.33, n s$. Overall error rates did not differ across the three groups $(M=5.82, S D=3.82)$. Results therefore confirmed our predictions: When women coped with stereotype threat "naturally," it led to cognitive control losses on a subsequent task; but this effect was buffered when women were given an adaptive coping strategy. Importantly, this subsequent task was a canonical measure of executive control and thus supports our prediction that stereotype threat spillover is a product of self-control loss.

Neural signals for control. How is threat-related executive control loss implemented in the brain? ERP analyses imply inefficient performance monitoring. Exposure to stereotype stress amplified the neural responses on the Stroop such that everything, especially low-conflict trials, was flagged as significant and attention-worthy. Analyses of the average neural response to error, congruent, and incongruent correct trials imply amplification because diagnostic group women had larger negative amplitudes than did the other two groups, $t(39)=2.23, p<.05, d=0.71$; the other two groups were similar, $t(39)=-0.94, n s$. Figure 4A, however, illustrates that responses to congruent trials were especially critical-threatened women had larger negative amplitude congruent waves than did men or reappraisal group women, $t(39)=2.28$, $p<.03, d=0.73$, whereas reappraisal group women had congruent waves comparable to those for men, $t(39)=0.48, n s$. After coping with stereotype stress, women showed brain patterns suggesting they were vigilant and anxious after all trial types but especially after the low-conflict trial type, for which vigilance and distress are superfluous and perhaps damaging.

Figure 4B illustrates that difference waveforms-the difference between responses to incongruent and congruent correct trialsdiffered by testing environment. Women exposed to stereotype threat had a larger difference wave than did men or reappraisal group women, $t(39)=-2.21, p<.05, d=0.71$, who did not differ from each other, $t(39)=-0.29, n s$. Importantly, unlike for the other two groups, the difference was positive for these women, with congruent trials resulting in larger negative waves than those for incongruent trials $(M=0.61 \mu \mathrm{V}, S D=0.82), t(14)=-2.91$, $p<.02, d=1.56$. Because this ERP indicates that events are significant and require strategic adjustment (Bartholow et al.,
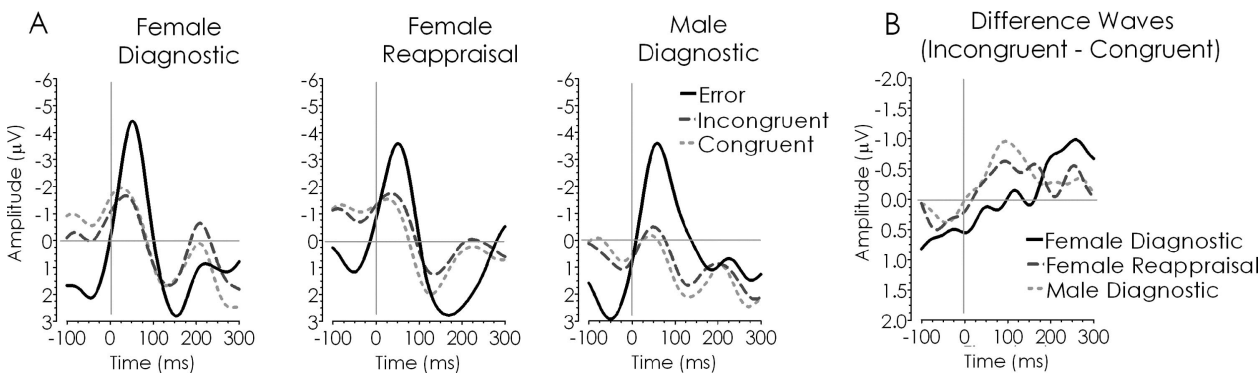

Figure 4. The effect of gender and test instruction on event-related-potential waveforms (A) and difference waves (B). 
2005), this result indicates that women who dealt with stereotype threat monitored their performance inefficiently, being more vigilant for low-conflict than high-conflict trials. This is a nonadaptive pattern of regulation-congruent trials, after all, are less attention-worthy than incongruent trials. In fact, the more that threatened women react to congruent trials with vigilant monitoring, the worse they may perform - a possibility we explore next.

Mediation and process. Figure 5 shows that this inefficient pattern of ACC activity significantly mediated the effect of stereotype threat on subsequent attempts at cognitive control. Following steps outlined for testing mediation, the grouping variable contrasting the female threat group with the male and female reappraisal groups predicted the congruent ERP $(\beta=-.34)$, $t(40)=2.27, p<.03, d=0.73$, and the congruent ERP predicted Stroop interference $(\beta=-.36), t(39)=-2.42, p<.02, d=0.78$. Together this constitutes a significant mediation effect, as determined by the $z^{\prime}=\alpha \beta / \sigma_{\alpha} \beta$ method $\left(z^{\prime}=1.74, p<.01\right)$, suggesting that changes in the congruent ERP wave partially accounted for the effects of testing environment on the Stroop task (MacKinnon, Lockwood, Hoffman, West, \& Sheets, 2002). ${ }^{5}$ This provides support for our hypothesis that coping with threatening environments impairs subsequent cognitive control attempts by affecting the ACC performance-monitoring system. Importantly, women who reappraise the situation do not show this pattern of neural inefficiency, suggesting that it is not stress per se that results in subsequent self-control loss but rather engaging in a coping strategy that demands executive resources.

We designed the test to be difficult for everyone $(M=5.19$, $S D=5.09$ ) and so did not expect diagnostic framing to affect performance, which it did not, $t(39)<1, n s$. However, even if performance were the same, people exposed to stereotype threat would need to work harder to get there (Eysenck \& Calvo, 1992), and the harder they worked, the more they should show impairments in self-control later on, an effect confirmed in Study 1. In the current study, that would translate to greater signs of inefficient ACC performance monitoring (i.e., higher neural distress signals after a congruent event). And this is precisely what we found: High performance predicted larger neural responses to congruent trials for women in the threat condition $(\beta=-.73), t(38)=-1.88, p<$ .05 (one-way), $d=0.63$, but not for men or women in the reappraisal condition $(\beta=.01), t(38)=0.05, n s$. Thus, high achievement on a threatening math test, although possible, incurs a cost on cognitive control later on. Importantly, women who took the test but who also used an adaptive coping strategy did not suffer when they performed well.

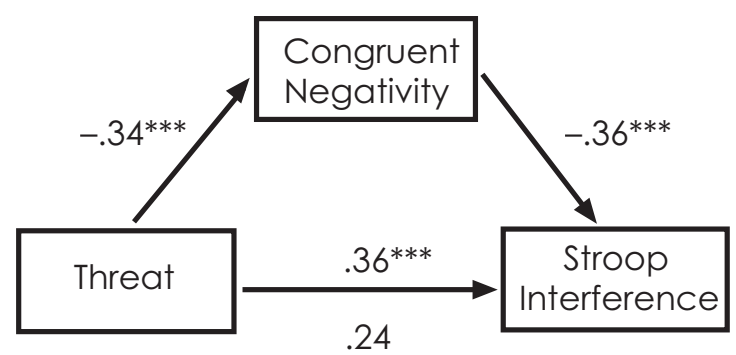

Figure 5. Mediation of the Stroop effect by congruent, low-conflict event-related potential $(\mathrm{Fz}){ }^{* * * *} p<.03$.
Unlike the other three studies, this study measured self-control directly and so provides strong support for our model of stereotype threat spillover. After coping with the stress of taking a diagnostic math test, women performed worse in an unrelated, nonstereotyped domain, this time inhibitory control. Because this effect was not evident for women who reappraised their emotions, it does not appear to be due to stress alone but rather to the resourcedemanding coping strategies normally used during stereotype threat. By examining self-control at the level of the brain, we gain further insight into the spillover effect. Women have less selfcontrol after coping with stereotype threat because they are vigilant for all types of events, especially ones that do not require further allocations of attention. This vigilance is not only unnecessary but also detrimental to control.

\section{Discussion}

In his novel Native Son, Richard Wright tells the story of the racial inequality and social injustices experienced by Bigger Thomas, an African American man living in 1930s inner-city Chicago. For Bigger, the experience of being a racial target is pervasive and inescapable. At the essence of his consciousness is "the old feeling that he had all his life: he was Black and had done wrong; White men were looking at something with which they would soon accuse him. It was an old feeling, hard and constant" (Wright, 1940, p. 206). Coping with a stigmatized social identity, in other words, acted as an undercurrent for everything he experienced. The present research indicates that this "hard and constant" undercurrent affects people's lives in many spheres and extends beyond traditionally stereotyped domains. This is consistent with Steele and colleagues' (2002) conceptualization of social identity threat and with Clark and colleagues' (1999) model of stigma as stressor, suggesting that identity threat can have consequences for stigmatized individuals in a broad range of domains.

In the current set of experiments, we examined whether risks associated with stereotype and social identity threat could spill over into domains traditionally considered to be stereotype-free. More specifically, we examined whether the effects of threat could spill over and interfere with self-control processes. In a series of four experiments, we found evidence indicating that stereotype and social identity threat have effects that extend beyond the stereotyped domain and into the realm of self-control. We found converging evidence for spillover across a broad range of domains related to aggression and hostility (Study 1), food intake (Study 2), judgment and decision making (Study 3), and basic attentional control (Study 4). Furthermore, we found this effect with a number of socially devalued groups including women (Studies 1, 2, and 4) and racial and religious minorities (Study 3). Taken together, the diversity of domains and affected groups extends Steele's (1997) original theory to reveal the potency of stereotype threat, which may extend far beyond performance in stereotyped domains.

\section{The Process of Stereotype Threat Spillover}

This work is compatible with theoretical formulations identifying stigma as a chronic stressor for devalued groups (Clark et al.,

\footnotetext{
${ }^{5} z^{\prime}$ uses a distribution other than the normal distribution. Critical values are available at https://docs.google.com/viewer?url=http://www.public .asu.edu/ davidpm/ripl/freqdist.pdf
} 
1999; Major \& O’Brien, 2005; Miller \& Kaiser, 2001). Stereotype and identity threat, like other stressors, result in a number of physiological, emotional, cognitive, and behavioral responses to cope with the situation. According to the integrated process model (Schmader et al., 2008), stereotype threat leads to impaired intellectual performance via three distinct responses, some involuntary and others not. The immediate response is (a) an involuntary physiological stress response, after which people voluntarily attempt to cope by (b) being vigilant about their performance and (c) regulating their thoughts and emotions. What connects all three is that they all tax the limited quantity of executive control individuals have at their disposal, which is the same resource needed to perform well on academic tests. In other words, the integrated process model indicates that coping with the stress of stereotype and identity threat hijacks self-control resources from other domains.

The current work suggests that these other domains extend far beyond academic performance. For example, when a woman discovers that she is one of only a handful of female students in her physics graduate program, she enters a threatening intellectual environment (Inzlicht \& Ben-Zeev, 2000) and may feel anxious and apprehensive (Spencer et al., 1999), may monitor what she says and how she says it (Inzlicht, Kaiser, \& Major, 2008), and may even try to suppress and deny her emotions so that others will not think less of her (Johns et al., 2008). All of these exact a toll on her executive control resources (Schmader \& Johns, 2003) and leave her prone to subsequent self-control failure. The result is that she may be less able to control her impulses even when she leaves the threatening environment - an effect that can lead her to overeat at the lunch counter, to react with aggression at the first signs of frustration, to pay less attention to the critical bits of a conversation, or to make less sound decisions when contemplating her future.

But why does threat affect performance in other regulatory domains? Although we have suggested that failures in the area of self-control are to blame, one must consider alternatives. The first alternative is that negative affect, specifically anxiety and anger, are responsible. Our data, however, do not support this interpretation. Not only did stereotype threat not increase self-reported negative emotionality, but when we controlled for emotionality, including controlling for anxiety and anger, our results were unchanged-threatened participants still aggressed (Study 1) and overate (Study 2). Furthermore, after being primed with a negative life event not involving discrimination, participants made sound, rational decisions, a pattern very much distinct from those primed with coping with discrimination (Study 4). We could make a similar argument for self-esteem and self-efficacy. Negative affect, low performance self-esteem, and low self-efficacy, therefore, do not appear to cause spillover.

It would also be hard to argue that stress-and stress alonecaused our effects. All the women who took the math tests in Studies 1, 2, and 4 received the same diagnostic test framing that past research has linked with evaluation apprehension and fear (Steele \& Aronson, 1995). As we observed in our studies, they also showed similar levels of self-reported negative emotion, indicative of experiencing similar levels of stress. What differentiates them, however, is not stress but coping. Half the women in each study were left to cope with the stress of stereotypes through whatever means they wished, most likely through some combination of emotion and thought suppression, both of which demand executive control resources (Johns et al., 2008). The other half used a coping strategy that is far easier on executive resources (Richards \& Gross, 2000) and were therefore saved from the type of spillover experienced by the others. So it is not stress per se but coping with stress in a resource-intensive way that leads to spillover, a result that is consistent with the strength model of self-control (Baumeister et al., 1999).

Thus far, we have eliminated a few alternatives and found some evidence in support of an account based on self-control failure. Our first and last studies also support this interpretation. In Study 4, we found direct evidence that stereotype threat reduced selfcontrol, this time on a canonical measure of executive function (Miyake et al., 2000): the Stroop task. Women who took a diagnostic test showed worse attentional control on a subsequent Stroop compared with men and with women who had the opportunity to reappraise their emotions. What's more, these same women showed inefficiencies in their neurally based performancemonitoring system. This system, based in the ACC, is important for self-control because it signals when control and attention are needed, usually after making mistakes or when facing challenging events. This type of attention, in contrast, is not normally needed for easy events (Bartholow et al., 2005). But this is precisely when threatened women's ACC control systems were engaged: They showed heightened performance monitoring after all types of events but especially after events that did not require further allocation of attention. Our results indicate that this was not only unnecessary but detrimental-the more that threatened women reacted to these events with vigilance and distress, the less control they had on the Stroop. Thus, we have more evidence that stereotype threat spillover is the product of self-control failure: It reaches the basic domain of inhibitory control and is mediated by inefficient performance monitoring.

The other evidence that supports a self-control failure interpretation is the negative relationship between performance on the threatening math test and indices of self-control on subsequent tasks. In Study 1, the better that threatened women did on the math test, the more aggressive they became afterward. In Study 4, the better they did, the greater the disruptions to subsequent performance monitoring. This is consistent with a loss of self-control explanation. Research on test taking indicates that people who suffer from test anxiety can succeed on all kinds of tests, but they have to work harder and expend more energy to do so (Eysenck \& Calvo, 1992). The same is true of stereotype threat, with some people challenged to expend greater energy and effort to overcome their group's bad reputation (Inzlicht, Aronson, et al., 2006). Although this can result in good performance in stereotyped domains, the consequence of this extra work is fewer executive resources for other activities later on. This is why, we suggest, the better that threatened women performed on the math test, the more aggressive they were in Study 1 and the more they showed inefficient performance monitoring in Study 4.

\section{Conclusions}

We rely on self-control processes to help us get through many of the seemingly menial tasks associated with daily living. Everyday events like getting out of bed when the alarm clock sounds, choosing a healthy sandwich over a burger and fries at lunchtime, or spending a beautiful summer afternoon working on a paper are 
all small victories of the self-control system. All of these victories combine to create functional, productive, and content individuals (Bandura, 1997). The underlying message of our research is that these small victories are less frequent for the stigmatized, the result of which has pervasive real-world implications. The "hard and constant" pressure of stereotype and social identity threat makes the battle between impulse and self-control, between fleeting desire and long-term goal, more difficult. In view of the broad scope of self-control, we suspect that stereotype threat spillover contributes to a number of societal problems, with aggression, obesity, risky decisions, and poor attention being only a small subset of these. A central challenge of future research will be to examine the breadth of problems to which stereotype threat spillover can contribute.

\section{References}

Ackerman, J. M., Goldstein, N. J., Shapiro, J. R., \& Bargh, J. A. (2009). You wear me out: The vicarious depletion of self-control. Psychological Science, 20, 326-332.

Aiken, L. S., \& West, S. G. (1991). Multiple regression: Testing and interpreting interactions. Thousand Oaks, CA: Sage.

Allison, K. W. (1998). Stress and oppressed social category membership. In J. K. Swim \& C. Stangor (Eds.), Prejudice: The target's perspective (pp. 145-170). San Diego, CA: Academic Press.

Aronson, J., Lustina, M. J., Good, C., Keough, K., Steele, C. M., \& Brown, J. (1999). When White men can't do math: Necessary and sufficient factors in stereotype threat. Journal of Experimental Social Psychology, $35,29-46$.

Bandura, A. (1997). Self-efficacy: The exercise of control. New York, NY: Freeman.

Bartholow, B. D., Pearson, M. A., Dickter, C. L., Sher, K. J., Fabiani, M., \& Gratton, G. (2005). Strategic control and medial frontal negativity: Beyond errors and response conflict. Psychophysiology, 42, 33-42.

Baumeister, R. F., Faber, J. E., \& Wallace, H. M. (1999). Coping and ego-depletion: Recovery after the coping process. In C. R. Snyder (Ed.), Coping: The psychology of what works (pp. 50-69). New York, NY: Oxford University Press.

Baumeister, R. F., \& Heatherton, T. F. (1996). Self-regulation failure: An overview. Psychological Inquiry, 7, 1-15.

Beilock, S. L., Rydell, R. J., \& McConnell, A. R. (2007). Stereotype threat and working memory: Mechanisms, alleviation, and spillover. Journal of Experimental Psychology: General, 136, 256-276.

Ben-Zeev, T., Fein, S., \& Inzlicht, M. (2005). Stereotype threat and arousal. Journal of Experimental Social Psychology, 41, 174-181.

Blascovich, J., Spencer, S. J., Quinn, D., \& Steele, C. (2001). African Americans and high blood pressure: The role of stereotype threat. Psychological Science, 12, 225-229.

Bless, H., Clore, G. L., Schwarz, N., Golisano, N., Rabe, C., \& Wolk, M. (1996). Mood and the use of scripts: Does a happy mood really lead to mindlessness? Journal of Personality and Social Psychology, 71, 665679.

Botvinick, M. M., Braver, T. S., Barch, D. M., Carter, C. S., \& Cohen, J. D. (2001). Conflict monitoring and conflict control. Psychological Review, 108, 624-652.

Brown, R. P., \& Day, E. A. (2006). The difference isn't Black and White: Stereotype threat and the race gap on Raven's Advanced Progressive Matrices. Journal of Applied Psychology, 91, 979-985.

Brown, R. P., \& Josephs, R. A. (2000). The importance of importance: The Mathematics Identification Questionnaire. Unpublished manuscript: University of Texas at Austin.

Brown, R. P., \& Pinel, E. C. (2003). Stigma on my mind: Individual differences in the experience of stereotype threat. Journal of Experimental Social Psychology, 39, 626-633.
Buntaine, R. L., \& Costenbader, V. K. (1997). Self-reported differences in the experience and expression of anger between girls and boys. Sex Roles, 36, 625-637.

Bushman, B. J., \& Baumeister, R. F. (1998). Threatened egotism, narcissism, self-esteem, and direct and displaced aggression: Does self-love or self-hate lead to violence? Journal of Personality and Social Psychology, 75, 219-229.

Cadinu, M., Maass, A., Rosabianca, A., \& Kiesner, J. (2005). Why do women underperform under stereotype threat? Psychological Science, $16,572-578$.

Chaiken, S., \& Trope, Y. (Eds.). (1999). Dual-process theories in social psychology. New York, NY: Guilford Press.

Clark, R., Anderson, N. B., Clark, V. R., \& Williams, D. R. (1999). Racism as a stressor for African Americans: A biopsychosocial model. American Psychologist, 54, 805-816.

Compas, B. E., Connor-Smith, J. K., Saltzman, H., Thomsen, A. H., \& Wadsworth, M. E. (2001). Coping with stress during childhood and adolescence: Problems, progress, and potential in theory and research. Psychological Bulletin, 127, 87-127.

Croizet, J. C., \& Claire, T. (1998). Extending the concept of stereotype threat to social class: The intellectual underperformance of students from low socioeconomic backgrounds. Personality and Social Psychology Bulletin, 24, 588-594.

Derks, B., Inzlicht, M., \& Kang, S. K. (2008). The neuroscience of stigma and stereotype threat. Group Processes \& Intergroup Relations, 11, $163-181$.

DeWall, C. N., Baumeister, R. F., Stillman, T. F., \& Gailliot, M. T. (2007). Violence restrained: Effects of self-regulation and its depletion on aggression. Journal of Experimental Social Psychology, 43, 62-76.

Dollard, J., Doob, L. W., Miller, N. E., Mowrer, O. H., \& Sears, R. R. (1939). Frustration and aggression. New Haven, CT: Yale University Press.

Eysenck, M. W., \& Calvo, M. G. (1992). Anxiety and performance: The processing efficiency theory. Cognition \& Emotion, 6, 409-434.

Gehring, W. J., Goss, B., Coles, M. G., \& Meyer, D. E. (1993). A neural system for error detection and compensation. Psychological Science, 4, 385-390.

Gervais, S. J., \& Vescio, T. K. (2007). Subtle sexism. In A. M. Columbus (Ed.), Advances in psychology (Vol. 49; pp. 137-166). New York, NY: Nova Science.

Glass, D. C., Singer, J. E., \& Friedman, L. N. (1969). Psychic cost of adaptation to an environmental stressor. Journal of Personality and Social Psychology, 12, 200-210.

Gonzales, P. M., Blanton, H., \& Williams, K. J. (2002). The effects of stereotype threat and double-minority status on the test performance of Latino women. Personality and Social Psychology Bulletin, 28, 659670

Gottfredson, M. R., \& Hirschi, T. (1990). A general theory of crime. Palo Alto, CA: Stanford University Press.

Gratton, G., Coles, M. G., \& Donchin, E. (1983). A new method for off-line removal of ocular artifact. Electroencephalography \& Clinical Neurophysiology, 55, 468-484.

Hajcak, G., \& Foti, D. (2008). Errors are aversive: Defensive motivation and the error-related negativity. Psychological Science, 19, 103-108.

Heatherton, T. F., \& Polivy, J. (1991). Development and validation of a scale for measuring state self-esteem. Journal of Personality and Social Psychology, 60, 895-910.

Herman, C. P., \& Polivy, J. (1980). Restrained eating. In A. Stunkard (Ed.), Obesity (pp. 208-255). Philadelphia, PA: Saunders.

Hochman, S. H. (1967). The effects of stress on Stroop color-word performance. Psychonomic Science, 9, 475-476.

Hofmann, W., Rauch, W., \& Gawronski, B. (2007). And deplete us not into temptation: Automatic attitudes, dietary restraint, and self-regulatory 
resources as determinants of eating behavior. Journal of Experimental Social Psychology, 43, 497-504.

Holding, D. H., Loeb, M., \& Baker, M. A. (1983). Effects and aftereffects of continuous noise and computation work on risk and effort choices. Motivation and Emotion, 7, 331-344.

Inzlicht, M., Aronson, J., Good, C., \& McKay, L. (2006). A particular resiliency to threatening environments. Journal of Experimental Social Psychology, 42, 323-336.

Inzlicht, M., \& Ben-Zeev, T. (2000). A threatening intellectual environment: Why females are susceptible to experiencing problem-solving deficits in the presence of males. Psychological Science, 11, 365-371.

Inzlicht, M., \& Gutsell, J. N. (2007). Running on empty: Neural signals for self-control failure. Psychological Science, 18, 933-937.

Inzlicht, M., Kaiser, C. R., \& Major, B. (2008). The face of chauvinism: How prejudice expectations shape perceptions of facial affect. Journal of Experimental Social Psychology, 44, 758-766.

Inzlicht, M., McKay, L., \& Aronson, J. (2006). Stigma as ego depletion: How being the target of prejudice affects self-control. Psychological Science, 17, 262-269.

Jamieson, J. P., \& Harkins, S. G. (2007). Mere effort and stereotype threat performance effects. Journal of Personality and Social Psychology, 93, $544-564$.

Johns, M., Inzlicht, M., \& Schmader, T. (2008). Stereotype threat and executive resource depletion: The influence of emotion regulation. Journal of Experimental Psychology: General, 137, 691-705.

Kahneman, D. (2003). A perspective on judgment and choice: Mapping bounded rationality. American Psychologist, 58, 697-720.

Krendl, A. C., Richeson, J. A., Kelley, W. M., \& Heatherton, T. F. (2008). The negative consequences of threat: A functional magnetic resonance imaging investigation of the neural mechanisms underlying women's underperformance in math. Psychological Science, 19, 168-175.

Lazarus, R. S., \& Folkman, S. (1987). Transactional theory and research on emotions and coping. European Journal of Personality, 13, 141-169.

Logel, C., Iserman, E. C., Davies, P. G., Quinn, D. M., \& Spencer, S. J. (2009). The perils of double consciousness: The role of thought suppression in stereotype threat. Journal of Experimental Social Psychology, 45, 299-312.

Luu, P., Collins, P., \& Tucker, D. M. (2000). Mood, personality, and self-monitoring: Negative affect and emotionality in relation to frontal lobe mechanisms of error monitoring. Journal of Experimental Psychology: General, 129, 43-60.

MacKinnon, D. P., Lockwood, C. M., Hoffman, J. M., West, S. G., \& Sheets, V. (2002). A comparison of methods to test mediation and other intervening variable effects. Psychological Methods, 7, 83-104.

Major, B., \& O’Brien, L. T. (2005). The social psychology of stigma. Annual Review of Psychology, 56, 393-421.

Masicampo, E. J., \& Baumeister, R. F. (2008). Toward a physiology of dual-process reasoning and judgment: Lemonade, willpower, and expensive rule-based analysis. Psychological Science, 19, 255-260.

Miller, C. T., \& Kaiser, C. R. (2001). A theoretical perspective on coping with stigma. Journal of Social Issues, 57, 73-92.

Miyake, A., Friedman, N. P., Emerson, M. J., Witzki, A. H., Howerter, A., $\&$ Wager, T. D. (2000). The unity and diversity of executive functions and their contributions to complex "frontal lobe" tasks: A latent variable analysis. Cognitive Psychology, 41, 49-100.

Muraven, M., \& Baumeister, R. F. (2000). Self-regulation and depletion of limited resources: Does self-control resemble a muscle? Self, 126, 247 259

O'Brien, L., \& Crandall, C. (2003). Stereotype threat and arousal: Effects on women's math performance. Personality and Social Psychology Bulletin, 29, 782-789.

Pascoe, E. A., \& Richman, L. S. (2009). Perceived discrimination and health: A meta-analytic review. Psychological Bulletin, 135, 531-554.

Pinel, E. C. (1999). Stigma consciousness: The psychological legacy of social stereotypes. Journal of Personality and Social Psychology, 76, $114-128$.

Richards, J. M., \& Gross, J. J. (2000). Emotion regulation and memory: The cognitive costs of keeping one's cool. Journal of Personality and Social Psychology, 79, 410-424.

Robinson, M. D., Schmeichel, B. J., \& Inzlicht, M. (2010). A cognitive control perspective on self-control strength and its depletion. Social and Personality Psychology Compass, 4, 189-200.

Schmader, T., \& Johns, M. (2003). Converging evidence that stereotype threat reduces working memory capacity. Journal of Personality and Social Psychology, 85, 440-452.

Schmader, T., Johns, M., \& Forbes, C. (2008). An integrated process model of stereotype threat effects on performance. Psychological Review, 115, $336-356$.

Spencer, S. J., Steele, C. M., \& Quinn, D. M. (1999). Stereotype threat and women's math performance. Journal of Experimental Social Psychology, 35, 4-28.

Steele, C. M. (1997). A threat in the air: How stereotypes shape intellectual identity and performance. American Psychologist, 52, 613-629.

Steele, C. M., \& Aronson, J. (1995). Stereotype threat and the intellectual test performance of African Americans. Journal of Personality and Social Psychology, 69, 797-811.

Steele, C. M., Spencer, S. J., \& Aronson, J. (2002). Contending with group image: The psychology of stereotype and social identity threat. Advances in Experimental Social Psychology, 34, 379-440.

Stone, J., Lynch, C. I., Sjomeling, M., \& Darley, J. M. (1999). Stereotype threat effects on Black and White athletic performance. Journal of Personality and Social Psychology, 77, 1213-1227.

Stucke, T. S., \& Baumeister, R. F. (2006). Ego depletion and aggressive behaviour: Is the inhibition of aggression a limited resource? European Journal of Social Psychology, 36, 1-13.

Swim, J. K., Hyers, L. L., Cohen, L. L., \& Ferguson, M. J. (2001). Everyday sexism: Evidence for its incidence, nature, and psychological impact from three daily diary studies. Journal of Social Issues, 57, $31-53$.

Tajfel, H., \& Turner, J. C. (1986). The social identity theory of inter-group behavior. In S. Worchel \& L. W. Austin (Eds.), Psychology of intergroup relations (pp. 7-24). Chicago, IL: Nelson-Hall.

Thaler, R., \& Johnson, E. J. (1990). Gambling with the house money and trying to break even: The effects of prior outcomes on risky choice. Management Science, 36, 643-660.

Vescio, T. K., Gervais, S. J., Snyder, M., \& Hoover, A. (2005). Power and the creation of patronizing environments: The stereotype-based behaviors of the powerful and their effects on female performance in masculine domains. Journal of Personality and Social Psychology, 88, 658 672.

Vohs, K. D., \& Heatherton, T. F. (2000). Self-regulatory failure: A resource-depletion approach. Psychological Science, 11, 249-254.

Walton, G. M., \& Cohen, G. L. (2003). Stereotype lift. Journal of Experimental Social Psychology, 39, 456-467.

Watson, D., Clark, L. A., \& Tellegen, A. (1988). Development and validation of brief measures of positive and negative affect: The PANAS scales. Journal of Personality and Social Psychology, 54, 1063-1070.

Wegner, D. M. (1994). Ironic processes of mental control. Psychological Review, 101, 34-52.

Wright, R. (1940). Native son. New York, NY: HarperCollins.

Yeung, N. C. J., \& von Hippel, C. (2008). Stereotype threat increases the likelihood that female drivers in a simulator run over jaywalkers. Accident Analysis \& Prevention, 40, 667-674.

Received July 21, 2008

Revision received December 18, 2009 Accepted December 22, 2009 